\title{
Analisis Pemasaran Pisang (Musa paradisiaca, L) Di Kota Langsa
}

\author{
Rozalina $^{1} /$ Aji Akbar $^{2}$ \\ ${ }^{1}$ Dosen Prodi Agribisnis Fakultas Pertanian \\ ${ }^{2}$ Alumni Prodi Agribisnis Fakultas Pertanian \\ UNIVERSITAS SAMUDRA
}

\section{RINGKASAN}

Analisis Pemasaran Pisang (Musa paradisiaca, L) Di Kota Langsa. Tujuan Penelitian adalah untuk mengetahui saluran pemasaran pisang di Kota Langsa, untuk mengetahui share margin pemasaran pisang pada masing-masing saluran pemasaran di Kota Langsa dan untuk mengetahui efisiensi pemasaran pisang di Kota Langsa.

Penelitian ini dilakukan dengan menggunakan metode survey. Lokasi penelitian di Kota Langsa dengan pertimbangan bahwa di Kota Langsa terdapat pedagang yang melakukan kegiatan pemasaran pisang. Penentuan desa sampel dilakukan dengan menggunakan metode Simple Random Sampling, jumlah sampel seluruhnya yaitu sebanyak 12 orang.

Terdapat 3 pola saluran pemasaran pisang di Kota Langsa. Efisiensi secara ekonomis dari sisi Share margin diketahui bahwa saluran pemasaran yang paling efisien yaitu terdapat pada saluran pemasaran III.

Sedangkan saluran pemasaran pisang di Kota Langsa dari sisi biaya pemasaran tidak efisien hal ini karena nilai nilai efisiensi dari ketiga saluran pemasaran $<50 \%$.

Kata kunci: Pemasaran, Pisang, Saluran, Efisiensi

\section{PENDAHULUAN \\ Latar Belakang}

Sektor pertanian merupakan sektor yang strategis dalam pembangunan nasional. Pengembangan pertanian saat ini masih mempunyai peranan dalam pengembangan ekonomi, terutama konstribusinya terhadap ketahanan pangan, kesempatan kerja dan lapangan usaha. Peran sektor pertanian dalam memacu perekonomian dapat dilihat lebih luas dari mendistribusikan hasil-hasil pembangunan kepada masyarakat.

Indonesia adalah salah satu negara pertanian yang sedang berkembang atau membangun, dimana $80 \%$ penduduknya bermata pencaharian pokok di sektor pertanian. Sektor pertanian merupakan sektor yang mempunyai peranan yang sangat penting dalam perekonomian nasional. Hal ini dapat dilihat dari banyaknya penduduk dan tenaga kerja yang hidup dan bekerja pada sektor pertanian (Adjib AD, 2001: 2).

Salah satu sasaran pembangunan pertanian antara lain adalah pembangunan pertanian yang mencakup peningkatan produksi pertanian tanaman pangan melalui berbagai usaha. Peningkatan produksi pangan seperti beras, palawija, dan produksi pangan yang berasal dari holtikultura adalah ditujukan untuk membantu terjaminnya cukup pangan dan memperbaiki taraf hidup petani dan keluarganya.

Pembangunan subsektor pertanian tanaman hortikultura merupakan salah satu bagian yang penting dari pembangunan pertanian. Salah satu komoditas tanaman hortikultura yang banyak digemari oleh masyarakat adalah pisang. Dahulu pisang pada umumnya merupakan tanaman sampingan untuk mengisi kekosongan tanah-tanah pekarangan atau tanah ladang dan jarang diusahakan secara intensif (Direktorat Jenderal Bina Produksi Hortikultura, 2009: 3). Sesuai dengan kemajuan teknologi tanaman pisang sudah dibudidayakan secara komersil dan intensif dalam suatu kebun khusus, sehingga hasil produksi dapat mencapai nilai optimum dan buah yang bermutu tinggi dan yang terpenting keuntungannya tidak kalah dengan tanaman lain.

Pisang merupakan tanaman ekonomi 
yang menguntungkan karena memiliki sifat pertumbuhan yang cepat yaitu pada umur rata-rata satu tahun telah dapat berbuah. Oleh sebab itu, bagi penanam modal dalam usahatani pisang, modalnya akan cepat berputar. "Sifat tanaman pisang yang kedua yaitu cepat berkembang biak, sehingga dalam satu tahun berikutnya tanaman sudah dapat berlipat ganda. Tanaman pisang juga dapat bertahan tehadap angin keras, musim kering, dan apabila mengalami kerusakan akan mudah pulih kembali" (Anonymous, 2003: 5).

Pisang segar yang dihasilkan petani tidak dapat disimpan dalam waktu yang relatif lama. Hal ini dikarenakan pisang bersifat mudah rusak (perishable), sehingga pisang harus segera didistribusikan ke konsumen. Proses pendistribusian pisang ke konsumen dilakukan melalui proses pemasaran. Pemasaran pisang pada dasarnya merupakan institusionalisasi pelayanan untuk menjembatani berpindahnya pisang dari sisi produksi ke sisi konsumsi. Pemasaran pisang yang baik akan mengalirkan pisang dari petani ke konsumen dan memberi indikasi tentang perubahan penawaran dan permintaan pisang kepada petani.

Faktor yang penting dalam memperlancar arus barang dari produsen ke konsumen adalah pemilihan saluran pemasaran yang tepat. Pemasaran adalah salah satu kegiatan yang dilakukan petani untuk mempertahankan kelangsungan usahataninya, dalam hal ini kegiatan jual beli untuk memperoleh keuntungan, sehingga setiap kegiatan pemasaran diperlukan analisis yang bertujuan untuk megetahui efisien atau tidaknya suatu salura pemasaran tersebut.

Analisis adalah suatu penganalisaan atau penyelenggaran untuk mempelajari berbagai masalah, dalam hal ini masalah pemasaran.Analisis pemasaran merupakan suatu analisis yang dilakukan untuk mengetahui tingkat keuntungan yang diperoleh petani dalam hal pemasara pisang.Salah satu peran penting dari pemasaran pisang adalah terbentuknya saluran pemasaran yang sistematis, terutama terlibatnya lembaga perantara seperti pedagang dan pengecer.

Saluran pemasaran antara satu dengan bagian lainya merupakan satu kesatuan yang saling bergantung sehingga membentuk pola pemasaran. Lembagalembaga pemasaran yang terlibat melakukan berbagai fungsi pemasaran yang terdiri dari fungsi pertukaran sehingga masing-masing lembaga tersebut mendapatkan bagian harga masing-masing atau disebut dengan Share margin. Bagian harga yang diterima masing-masing lembaga pemasaran apabila pembagiannya adil dari keseluruhan harga yang di bayar konsumen akhir dari semua pihak yang ikut serta didalam seluruh kegiatan produksi dan pemasaran barang itu maka saluran pemasaran tersebut disebut efisien.

Strategi pemasaran meliputi sistem yang berhubungan dengan tujuan untuk merencanakan dan menentukan harga sampai dengan mempromosikan dan mendistribusikan barang dan jasa yang bisa memuaskan kebutuhan pembeli. Perencanaan strategi pemasaran memberikan dasar bagi petani untuk mengambil langkah yang efektif untuk masa yang akan datang.

\section{Rumusan Masalah}

1. Ada berapa saluran pemasaran pisang di Kota Langsa?

2. Berapa besar share margin dan margin pemasaran pisang pada masing- masing saluran pemasaran di Kota Langsa?

3. Bagaimana efisiensi pemasaran pisang diKota Langsa?

\section{Tujuan Penelitian}

1. Untuk mengetahui saluran pemasaran pisang di Kota Langsa.

2. Untuk mengetahui share margin $\mathrm{dn}$ margin pemasaran pisang pada masing masing saluran pemasaran di Kota Langsa

3. Untuk mengetahui efisiensi pemasaran pisang di Kota Langsa.

\section{Hipotesis Penelitian}

Pemasaran pisang di Kota Langsa 
sudah efisien

\section{METODOLOGI PENELITIAN}

Lokasi, Objek, Ruang Lingkup dan Waktu Penelitian

Penelitian ini dilakukan di Kota Langsa. Metode penelitian yang digunakan dalam penelitian ini adalah metode survey. Menurut Nazir (2009: 550), "Metode survey adalah penyelidikan untuk memperoleh fakta dari gejala-gejala dan mencari keteranganketerangan secara faktual, baik tentang institusi sosial, ekonomi ataupun politik dari suatu kelompok atau suatu daerah". Penelitian ini dilaksanakan di Kota Langsa, dengan pertimbangan bahwa di Kota Langsa terdapat pedagang yang melakukan kegiatan pemasaran pisang. Objek dalam penelitian ini hanya dibatasi pada petani, pedagang dan konsumen yang melakukan pemasaran pisang yang ada di Kota Langsa. Ruang lingkup penelitian ini meliputi efisiensi pemasaran pisang di Kota Langsa.

\section{Teknik Penentuan Sampel dan Pengumpulan} Data

Kota Langsa terdiri dari 5 kecamatan. Dari 5 kecamatan diambil 2 kecamatan secara Purposive Sampling. Sugiyono (2008: 11) Tabel III-1 Jumlah Populasi dan Sampel Petani Pisang di Kota Langsa, 2016

\begin{tabular}{|c|c|c|c|}
\hline No. & Kecamatan & $\begin{array}{c}\text { JumlahPopulasi } \\
\text { (Orang) }\end{array}$ & $\begin{array}{c}\text { JumlahSampel } \\
\text { (Orang) }\end{array}$ \\
\hline 1 & Langsa Kota & 10 & 5 \\
2 & Langsa Lama & 14 & 7 \\
\hline \multicolumn{2}{|c|}{ Jumlah } & 24 & 12 \\
\hline
\end{tabular}

Sumber: Data primer, 2016 (diolah)

Dari Tabel III-1 dapat dilihat bahwa jumlah populasi seluruhnya yaitu sebanyak 24 orang. Dari 24 orang tersebut di ambil sampel sebanyak 12 orang yang terdiri dari kecamatan Langsa Kota 5 orang dan Kecamatan Langsa Lama sebanyak 7 orang.

Lembaga pemasaran dalam penelitian ini terdiri dari 3 lembaga pemasaran yaitu: agen desa, agen kecamatan dan pedagang pengecer. Pengambilan sampel untuk mengemukakan Purposive Sampling adalah sampling yang dilakukan dengan pertimbangan tertentu. Kecamatan yang dipilih dalam penelitian ini dengan pertimbangan bahwa kecamatan tersebut merupakan daerah yang memiliki usahatani pisang dan memasarkannya.

Pengambilan petani sampel dilakukan dengan menggunakan metode Simple Random Sampling (Sampel Acak sederhana). Nazir, M (2009: 23) menyatakan bahwa Simple Random Sampling adalah pengambilan sampel dari populasi dimana tiap unit populasi mempunyai peluang yang sama untuk dipilih. Sedangkan Sudjana (2005: 13) menyatakan: "bila populasi kecil, sampel dirumuskan mendekati jumlah populasi, misalnya bila populasi 1000 kasus menarik sampel $10-20 \%$ telah cukup memadai, namun bila populasi 50 kasus sampel tidak kurang dari 20\%". Besarnya sampel yang diambil adalah $50 \%$ dari jumlah petani di daerah penelitian.

Penelitian langsung merandom atau mengacak untuk mendapatkan ukuran sampel yang diinginkan. Adapun jumlah populasi dan sampel sebagai berikut: lembaga pemasaran dilakukan dengan metode pengambilan sampel secara sensus, hal ini dikarenakan jumlah populasi lembaga pemasaran di daerah penelitian relatif kecil. "Istilah lain sampel jenuh adalah sensus, dimana semua anggota populasi dijadikan sampel (Sugiyono, 2008: 124). Adapun jumlah lembaga pemasaran di Kota Langsa sebagai berikut: 
Tabel III-2 Jumlah Populasi, Agen dan Pedagang Pisang di Kota Langsa, 2016

\begin{tabular}{|c|l|c|c|}
\hline No. & \multicolumn{1}{|c|}{ Desa Sampel } & $\begin{array}{c}\text { Jumlah Populasi } \\
\text { (Orang) }\end{array}$ & $\begin{array}{c}\text { Jumlah Sampel } \\
\text { (Orang) }\end{array}$ \\
\hline 1 & Agen Desa & 4 & 4 \\
2 & Agen Kecamatan & 3 & 3 \\
3 & Pedagang Pengecer & 8 & 8 \\
\hline \multicolumn{2}{|l|}{ Jumlah } & 15 & 15 \\
\hline
\end{tabular}

Sumber: Data primer, 2016 (diolah)

Berdasarkan tabel III-2 dapat dilihat bahwa lembaga pemasaran untuk agen desa sebanyak 4 orang, agen kecamatan 3 orang dan pedagang pengecer 8 orang sehingga jumlah seluruh lembaga pemasaran dalam hal ini agen dan pedagang berjumlah seluruhnya 15 orang.

\section{Pengumpulan Data}

Data yang dikumpulkan dalam penelitian ini meliputi data primer dan sekunder. Data primer terdiri dari produksi, data pemasaran, keadaan distribusi dan data harga. Sedangkan data sekunder adalah sumber dari instansi-instansi terkait yang berhubungan dengan penelitian. Data primer diperoleh dengan cara: Observasi, Wawancara dan Kuisioner. Pengumpulan data sekunder dalam penelitian ini dilakukan dengan cara sebagai berikut: Proses membaca, Mempelajari dan mengambil keterangan yang diperlukan dari buku, bahan kuliah serta sumber lainnya yang berhubungan dengan penelitian ini dan bahan kepustakaan yaitu dengan mengumpulkan data teori-teori yang diperoleh dari literatur-literatur yang terkait dengan permasalahan yang ada dalam penulisan skripsi.

\section{Konsep Operasional Variabel}

1. Produsen adalah orang yang menghasilkan barang dan jasa untuk dijual atau dipasarkan

2. Lembaga pemasaran adalah individu yang menyelenggarakan aktivitas pemasaran, menyalurkan jasa dan produk pertanian kepada konsumen akhir.

3. Saluran pemasaran adalah sekelompok organisasi yang saling bergantung dan terlibat dalam proses pembuatan produk dan jasa yang digunakan untuk dikonsumsi

4. Harga pisang adalah suatu nilai tukar atau uang yang dibayar lembaga pemasaran untuk membeli pisang yang dihitung dalam rupiah per sisir.

5. Biaya pemasaran adalah semua biaya saat produk selesai diproduksi dan disimpan dalam gudang sampai produk tersebut ditukar dengan uang tunai.

\section{Metode Analisis dan Pengujian Hipotesis}

\section{Saluran Pemasaran}

Mengetahui saluran pemasaran yang dilakukan dengan cara mengikuti aliran produksi dari petani sampai konsumen akhir.

\section{Biaya Pemasaran}

Biaya pemasaran adalah biaya yang dikeluarkan untuk keperluan pemasaran. Besarnya biaya pemasaran dapat dirumuskan sebagai berikut:

$$
\begin{array}{ll}
\mathrm{Bp}=\mathrm{Bp} 1+\mathrm{Bp} 2+\ldots .+\mathrm{Bp} \\
\text { Dimana: } & \mathrm{Bp}=\text { Biaya pemasaran } \\
& \mathrm{Bp} 1 . . \mathrm{n}=\text { Biaya pemasaran }
\end{array}
$$
tiap lembaga

\section{Margin Pemasaran}

Margin pemasaran adalah perbedaan antara apa yang dibayar oleh konsumen dan apa yang diterima oleh produsen untuk produk pertaniannya.

$\mathrm{Mp}=$ Pri-Pfi atau $\mathrm{Mji}=\mathrm{Bi}+$ Ki..........................(Soekartawi, 2001: 54)

Dimana:

$\mathrm{Mp}=$ Margin pemasaran pisang

$\mathrm{Pr}=$ Harga di tingkat kosumen

$\mathrm{Pf}=$ Harga di tingkat petani

Share Margin

$\mathrm{Sm}=\mathrm{Pp} / \mathrm{Pk} \times 100 \%$. (Soekartawi, 
Dimana:

Sm = Persentase margin

$\mathrm{Pp}=$ Harga yang diterima produsen dan pedagang

$\mathrm{Pk}=$ Harga yang dibayar konsumen akhir

\section{Efisiensi Pemasaran}

$\mathrm{EP} \quad \mathrm{BP} / \mathrm{HE} \quad \mathrm{x}$

100\%.......................(Soekartawi, 2001: 60)

Di mana :

$E P=$ Efisiensi Pemasaran

$\mathrm{BP}=$ Biaya Pemasaran

$\mathrm{HE}=$ Harga Eceran

Kaidah pengambilan keputusan efisiensi pemasaran ini adalah

- EP sebesar 0-50\% maka saluran pemasaran efisien

- EP > 50\% maka saluran pemasaran kurang efisien

\section{Saluran Pemasaran Pisang}

Pola saluran pemasaran pisang dapat diketahui dengan cara mengikuti arus pemasaran pisang mulai dari petani hingga sampai kepada konsumen. Berdasarkan penelitian yang telah di laksanakan, dapat diketahui pola pemasaran Pisang di Kota Langsa adalah sebagai berikut:

a. Pola saluran Pemasaran I; Petani $\rightarrow$ Agen Desa $\rightarrow$ Agen Kecamatan $\rightarrow$ Agen

\section{HASIL PENELITIAN DAN PEMBAHASAN}

Karakteristik Petani dan Pedagang

Karakteristik petani pisang di Kota Langsa terdiri atas umur yaitu dengan nilai 38,50 tahun, pendidikan rata-rata petani pisang di Kota Langsa yaitu selama 8,42 tahun, tanggungan yang dimiliki petani yaitu 3 orang, sehingga petani harus berusahatani pisang secara intensif untuk memenuhi kebutuhan dan pengalaman petani pisang di Kota Langsa selama 5,25 tahun.

Rata-rata umur lembaga pemasaran yang terdiri dari agen desa, agen kecamatan dan pedagang pengecerpisangdidaerah penelitian adalah 39,53 tahun, tingkat pendidikan rata-rata 9,27 tahun, pengalaman di bidang berdagang rata-rata 7,00 tahun yang tergolong dan jumlah tanggungan keluarga rata-rata 3,00 orang yang termasuk jumlah tanggungan sedikit.

\section{pengencer $\rightarrow$ Konsumen}

b. Pola Saluran Pemasaran II: Petani $\rightarrow$ Agen Kecamatan $\rightarrow$ Pedagang Pengencer $\rightarrow$ Konsumen

c. Pola saluran pemasaran III: Petani $\rightarrow$ Pedagang pengencer $\rightarrow$ Konsumen

Adapun jumlah petani berdasarkan saluran pemasaran pisang yang digunakan adalah mendistribusikan pisang dapat dilihat pada tabel V- 3 berikut.

Tabel V-3. Jenis Saluran Pemasaran dan Jumlah petani Responden di Kota Langsa

\begin{tabular}{|l|l|c|r|}
\hline No & Saluran Pemasaran & Jumlah Petani & Persentase \% \\
\hline 1 & Saluran I & 3 & 25,00 \\
2 & Saluran II & 4 & 33,33 \\
3 & Saluran III & 5 & 41,66 \\
\hline \multicolumn{2}{r|}{ Jumlah } & 12 & 100,00 \\
\hline
\end{tabular}

Sumber : Data primer diolah, 2016

Berdasarkan tabel V- 3 diatas dapat dilihat bahwa saluran pemasaran yang paling banyak digunakan petani adalah saluran pemasaran III yaitu sebanyak 5orang $(41,66 \%)$ dimana petani langsung menjual pisangkepada pedagang pengencer. Selanjutnya saluran II sebanyak 4 orang $(33,33 \%)$ dan saluran I sebanyak 3 orang $(25,00 \%)$. Saluran pemasaran III paling banyak dibandingkan saluran Idan II sehingga keuntungan yang diperoleh petani lebih banyak dibandingkan dengan menggunakan saluran I dan II, hal ini disebabkan saluran pemasaran III yang digunakan petani lebih pendek dibanding saluran I dan II.

\section{Fungsi-fungsi pemasaran}

Fungsi-fungsi pemasaran merupakan hal yang penting dalam proses pemasaran Pisang. Setiap lembaga pemasaran melakukan fungsinya sesuai dengan kebutuhan lembaga itu. Berdasarkan hasil 
penelitian di peroleh fungsi-fungsi pemasaran yang dilakukan oleh setiap lembaga pemasaran Pisang di setiap jenis saluran pemasaran.

\section{Biaya Pemasaran Pisang}

Proses mengalirnya barang dari produser ke konsumen memerlukan biaya, dengan adanya biaya pemasaran maka suatu produk akan meningkat harganya. Semakin panjang rantai pemasaran maka biaya yang dikeluarkan dalam pemasaran akan semakin meningkat. Selainitu, besarnya biaya pemasaran suatu produk tergantung pada jenis perlakuan terhadap produk itu sendiri. Adapun biaya pemasaran pisang dalam penelitian ini yaitu seluruh biaya yang dikeluarkan lembaga pemasaran dalam proses pengangkutan yaitu pembelian tali untuk mengikat pisang dan bensin untuk alat transportasi. Untuk lebih jelasnya rata-rata pengunaan biaya pemasaran pisang di Kota Langsa dapat dilihat pada tabel V-5 berikut.

Tabel V-5. Rata-rata Biaya Pemasaran Pisang di Kota Langsa

\begin{tabular}{|c|c|c|c|c|c|}
\hline \multirow{3}{*}{ No } & \multirow{3}{*}{$\begin{array}{c}\text { Saluran } \\
\text { Pemasaran }\end{array}$} & \multicolumn{3}{|c|}{ Biaya Pemasaran (Rp/Sisir) } & \multirow[t]{2}{*}{ Jumlah Total } \\
\hline & & $\begin{array}{l}\text { Agen } \\
\text { Desa }\end{array}$ & $\begin{array}{c}\text { Agen } \\
\text { Kecamatan }\end{array}$ & $\begin{array}{l}\text { Pedagang } \\
\text { Pengencer }\end{array}$ & \\
\hline & & $B P_{1}$ & $B P_{2}$ & $B P_{3}$ & $B P=B P_{1}+B P_{2}+B P_{3}$ \\
\hline 1 & 1 & 219 & 177 & 153 & 549 \\
\hline 2 & II & 0 & 310 & 256 & 566 \\
\hline 3 & III & 0 & 0 & 162 & 162 \\
\hline
\end{tabular}

Sumber : Data primer diolah 2016

Berdasarkan tabel V-5 di atas dapat dilihat bahwa pada saluran I Agen Desa membeli pisang dari petani dengan mengeluarkan biaya pemasaran pisangRp. 219 per sisir, Agen Kecamatan membeli pisang dari agen desa dengan mengeluarkan biaya pemasaran Rp. 177 per sisir, selanjutnya pedagang pengecer membeli pisang dari agen Kecamatan dengan mengeluarkan biaya pemasaran Rp. 153 per sisir, sehingga total biaya pemasaran pada saluran I adalah Rp. 549 per sisir.

Tabel di atas juga menunjukkan bahwa pada saluran II Agen Desa tidak terlibat dalam pemasaran pisang, sehingga Agen Kecamatan langsung membeli pisang dari petani dengan mengeluarkan biaya pemasaran lebih besar dari pada membeli pada agen desa saluran I yaitu Rp. 310 per sisir mengigat tempat usahatani pisang yang diperoleh dengan jarak tempuh yang jauh, selanjutnya pedagang pengecer membeli pisang dari agen Kecamatan dengan mengeluarkan biaya pemasaran Rp. 256 per sisir, sehingga total biaya pemasaran pada saluran II adalah Rp. 566 per sisir.

Pada saluran III agen Desa dan Agen Kecamatan tidak terlibat dalam pemasaran pisang sehingga Pedagang Pengecer langsung membeli pisang pada petani dengan mengeluarkan biaya Rp. 162 per sisir, hal ini menujukkan biaya yang dikeluarkan lebih sedikit dari pada saluran I dan saluran II. Rata-rata pola pemasaran yang paling banyak mengeluarkan biaya pemasaran adalah saluran pemasaran II yaitu sebesar Rp. 566,dan rata-rata pola pemasaran yang paling sedikit mengeluarkan biaya pemasaran adalah saluran pemasaran III yaitu Rp. 162,. Biaya pemasaran padasaluran III lebih kecil dari pada biaya pemasaran pada saluran I dan II karena lembaga pemasaran yang terlibat pada saluran III tersebut hanya satu yaitu pedagang pengencer jadi biaya yang dikeluarkan hanya sedikit.

\section{Margin Pemasaran Pisang}

Margin pemasaran sering digunakan sebagai indikator efisiensi pemasaran. Besarnya margin pemasaran pada berbagai saluran pemasaran dapat berbeda, karena tergantung pada panjang pendeknya saluran pemasaran dan aktifitas-aktifitas yang telah dilaksanakan serta keuntungan yang diharapkan oleh lembaga pemasaran yang terlibat dalam pemasaran. Untuk lebih jelasnya mengenai rata-rata margin dan keuntungan pemasaran pisangdidaerah 
penelitian dapat dilihat pada tabel V-6 berikut:

Tabel V-6. Rata-rata Margin Pemasaran di Kota Langsa

\begin{tabular}{|c|c|c|c|c|c|}
\hline \multirow{3}{*}{ No } & \multirow{3}{*}{$\begin{array}{l}\text { Saluran } \\
\text { Pemasaran }\end{array}$} & \multicolumn{3}{|c|}{ Margin Pemasaran (Rp/Sisir) } & \multirow[t]{2}{*}{ Jumlah (Rp/Sisir) } \\
\hline & & $\begin{array}{l}\text { Agen } \\
\text { Desa }\end{array}$ & $\begin{array}{c}\text { Agen } \\
\text { Kecamatan }\end{array}$ & $\begin{array}{l}\text { Pedagang } \\
\text { Pengencer }\end{array}$ & \\
\hline & & Mj 1 & Mj 2 & Mj 3 & $M j=M j 1+M j 2+M j 3$ \\
\hline 1 & I & 2000 & 1000 & 1000 & 4000 \\
\hline 2 & II & 0 & 1000 & 1000 & 2000 \\
\hline 3 & III & 0 & 0 & 1000 & 1000 \\
\hline
\end{tabular}

Sumber : Data primer diolah, 2016

Berdasarkan tabel V-6 diatas dapat dilihat bahwa rata-rata margin pemasaran yang paling kecil didapat ialah oleh pedagang pengecer pada saluranpemasaran III yaitu sebesar Rp. 1.000,-, sedangkan rata-rata margin pemasaran yang paling banyak didapat adalah oleh agen desa pada saluran pemasaran I yaitu sebesar Rp. 2000,-. Margin pemasaran pada saluran III paling kecil dikarenakan pengeluaran biaya pemasaran lebih sedikit dan pedagang pengecer pada saluran III tersebut menjual pisangdengan harga yang lebih tinggisehingga keuntungan yang diperoleh pada saluran ini lebih tinggi dibanding lembaga pemasaran yang lain.

\section{Efisiensi Pemasaran Pisang}

Efisiensi pemasaran dapat dilihat dari Share Margin dan biaya pemasaran. Share Margin yang dimaksud dalam penelitian ini adalah bagian yang diterima oleh masing-masing lembaga pemasaran. Dari hasil perhitungan Share Margindapat diketahui besar margin keuntungan yang diterima oleh masing- masaing lembaga pemasaran. Untuk jelasnya tentang rata-rata Share Marginyang diterima oleh tiap-tiap lembaga pemasaran didaerah penelitian dapat dilihat pada tabel V-7 berikut ini.

Tabel V-7. Rata-rata Share Margin yang diterima oleh tiap-tiap lembaga Pemasaran di Kota Langsa

\begin{tabular}{|c|c|c|c|c|l|c|}
\hline No & \multirow{2}{*}{$\begin{array}{c}\text { Saluran } \\
\text { Pemasaran }\end{array}$} & \multicolumn{3}{|c|}{ Share Margin \% } & $\begin{array}{c}\text { Jumlah } \\
\text { Total Share } \\
\text { Margin (\%) }\end{array}$ & $\begin{array}{c}\text { Rata- } \\
\text { rata } \\
(\%)\end{array}$ \\
\cline { 2 - 7 } & $\begin{array}{c}\text { Agen } \\
\text { Desa }\end{array}$ & $\begin{array}{c}\text { Agen } \\
\text { Kecamatan }\end{array}$ & $\begin{array}{l}\text { Pedagang } \\
\text { Pengecer }\end{array}$ & & \\
\hline 1 & I & 38,00 & 69,00 & 88,00 & 194 & 65 \\
2 & II & 0,00 & 69,00 & 88,00 & 156 & 78 \\
3 & III & 0,00 & 0,00 & 88,00 & 88 & 88 \\
\hline
\end{tabular}

Sumber Data primer diolah

Berdasarkan Tabel V-7 di atas dapat terlihat jumlah Share margin yang diterima oleh masing-masing lembaga pemasaran di daerah penelitian dalam pemasaran Pisang. Berdasarkan tabel tersebut juga diketahui bahwa saluran pemasaran yang paling efisien yaitu terdapat pada saluran pemasaran III yaitu rata-rata share margin $88 \%$. Namun semua saluran pemasaran I, II dan III sudah efisien dari sisi share margin karena rata-rata nilai $\geq 50 \%$.

'Menurut pendapat Sudiyono (2002: 17) "efisiensi pemasaran terjadi bila biaya pemasaran dapat ditekan sehingga keuntungan pemasaran dapat lebih tinggi". Untuk melihat efisiensi pemasaran pisang di Kota Langsa sebagaimana tabel berikut: 
Tabel V-8 : $\quad$ Jumlah Efisiensi Pemasaran Pisang di Kota Langsa

\begin{tabular}{|l|c|c|c|c|l|l|}
\hline \multirow{2}{*}{ No } & \multirow{2}{*}{$\begin{array}{c}\text { Saluran } \\
\text { Pemasaran }\end{array}$} & $\begin{array}{c}\text { Agen } \\
\text { Desa }\end{array}$ & $\begin{array}{c}\text { Agen } \\
\text { Kecamatan }\end{array}$ & $\begin{array}{c}\text { Pedagang } \\
\text { Pengecer }\end{array}$ & $\begin{array}{c}\text { Jumlah } \\
\text { Efisiensi }\end{array}$ & \multirow{2}{*}{ Kesimpulan } \\
\hline 1. & I & 13,10 & 8,15 & 5,73 & 26,98 & Efisien \\
2. & II & 0 & 19,00 & 8,00 & 27,33 & Efisien \\
3. & III & 0 & 0 & 10,13 & 10,13 & Efisien \\
\hline
\end{tabular}

Sumber: Data primer diolah, 2016

Berdasarkan tabel di atas dapat dilihat bahwa saluran pemasaran pisang di Kota Langsa dari sisi biaya pemasaran tidak efisien hal ini karena nilai efisiensi di setiap lembaga pemasaran $<50 \%$.

\section{KESIMPULAN DAN SARAN}

\section{Kesimpulan}

1. Terdapat tiga saluran pemasaran pisang yang digunakan petani di Kota Langsa dalam menyampaikan hasil produksinya, yaitu:

2. Pola saluran pemasaran I: Petani ke agen Desa ke Agen Kecamatan ke pedagang pengecer ke konsumen

3. Pola saluran pemasaran II: Petani ke ke Agen Kecamatan ke pedagang pengecer ke konsumen

4. Pola pemasaran saluran III: Petani langsung ke pedagang pengecer ke konsumen

5. Efisiensi secara ekonomis dari sisi Share margin diketahui bahwa saluran pemasaran yang paling efisien yaitu terdapat pada saluran pemasaran III. Sedangkan saluran pemasaran pisang di Kota Langsa dari sisi biaya pemasaran tidak efisien hal ini karena nilai nilai efisiensi dari ketiga saluran pemasaran $<50 \%$.

\section{Saran}

1. Informasi harga pasar sangat diperlukan petani agar bisa mendapatkan keuntungan lebih besar.

2. Untuk meningkatkan pendapatan, diharapkan petani melakukan penjualan produksinya dengan memilih saluran yang terpendek.

\section{DAFTAR PUSTAKA}

Adieutomo \& Samosir. 2010. Dasar-dasar Demografi. edisi $2 . \quad$ Jakarta: Salemba Empat

Adjib, AD. 2001. Agribisnis. Jakarta: Yayasan Pengembangan Sinar Tani

Ance Gunarsih. 2006. Klimatologi, Pengaruh Iklim Terhadap Tanah dan Temperatur. Jakarta: Bina Aksara

Direktorat Jenderal Bina Produksi Hortikultura. 2009. Buku Pintar Pembenihan. Jakarta Fandy Tjiptono. 2008. Strategi Bisnis Pemasaran. Yogyakarta: Andi

Kotler, Phillip. 2005. Dasar-dasar pemasaran. Jakarta: Erlangga

Martodireso, S, AW. 2002. Agribisnis Kemitraan. Yogyakarta: Usaha Bersama

Massofa. 2008. Pengertian dan Faktorfaktor yang Mempengaruhi Produktivitas

Kerja. (On Line), http://massofa.wordpress.com, 15 Juli - 2015. Mubyarto. 2008. Pengantar Ekonomi Pertanian. Jakarta: Pustaka LP3ES Nazir, M. 2009. Metode Penelitian. Jakarta: PT. Ghalia Indonesia Netisemito, A,S,2005. Marketing. Jakarta: Ghalia Indonesia

Prajnanta. 2004. Agribisnis Cabai Hibrida. Jakarta: Penebar Swadaya

Rukmana, R. 2000. Bertanam Pisang. Yogyakarta: Kanisius.

Sudiyono. 2002. Pemasaran Pertanian. Malang Universitas Muhamadiyah Malang. Soekartawi. 2001. Analisis Usahatani. Jakarta: UI-Press

Swastha. 2000. Pengantar Bisnis Modern, Pengantar Ekonomi Perusahaan 
Modern. Jakarta: Liberty

Sudjana. 2005. Teknik Analisa Regresi dan Korelasi. Bandung: Tarsito

Sugiyono, 2008. Metode Penelitian Kunatitatif Kualitatif dan R\&D.
Bandung: Alfabeta

Tjitrosoepomo. G. 2000. Morfologi

Tumbuhan. Yogyakarta: Gadjah Mada University Press. 